\section{One size doesn't fit all: time to revisit patient- reported outcome measures (PROMs) in paediatric ophthalmology?}

V Tadić ${ }^{1,2}$ and JS Rahi $1,2,3,4$

for the Child Vision PROMs group ${ }^{5}$

\begin{abstract}
The purpose of this article is to summarise methodological challenges and opportunities in the development and application of patient reported outcome measures (PROMs) for the rare and complex population of children with visually impairing disorders. Following a literature review on development and application of PROMs in children in general, including those with disabilities and or/chronic condition, we identified and discuss here $5 \mathrm{key}$ issues that are specific to children with visual impairment: (1) the conflation between theoretically distinct vision-related constructs and outcomes, (2) the importance of developmentally appropriate approaches to design and application of PROMs, (3) feasibility of standard questionnaire formats and administration for children with different levels of visual impairment, (4) feasibility and nature of selfreporting by visually impaired children, and (5) epidemiological, statistical and ethical considerations. There is an established need for vision-specific age-appropriate PROMs for use in paediatric ophthalmology, but there are significant practical and methodological challenges in developing and applying appropriate measures. Further understanding of the characteristics and needs of visually impaired children as questionnaire respondents is necessary for development of quality PROMs and their meaningful application in clinical practice and research.

Eye (2017) 31, 511-518; doi:10.1038/eye.2016.316; published online 13 January 2017
\end{abstract}

\section{Introduction}

Understanding and capturing patients' perspectives of their health and impact of healthcare is now recognised as a key component of effective, patient-centred services. ${ }^{1-3}$ Patient-reported outcome measures (PROMs) are increasingly advocated and used to achieve this. ${ }^{4-6}$ PROMs are questionnaire instruments measuring any outcome related to health, illness or treatment that are directly reported by patients themselves. Different PROMs assess different health constructs. These include health-related quality of life (HRQoL), wellbeing, health status, functional status, participation, and symptoms (eg, pain severity). They are seen as having a potential to improve services and healthcare, by providing validated and standardised patient-assessed evidence of effectiveness and quality at the same time as facilitating interactions between professionals and patients and supporting shared decisionmaking. Increasingly, they are used to evaluate outcomes of new interventions in the context of trials or in studies of natural history.

Importantly, PROMs are to be distinguished from patient-reported experience measures (PREMs), which are used to capture the process of and specific experiences during healthcare (eg, whether the patient was seen on time), as opposed to outcomes of healthcare (eg, change in functional ability or symptoms). ${ }^{7}$

The need for and value of PROMs is well established in paediatric and child health. ${ }^{8,9}$ A plethora of influential and widely used PROMs for children now exists that capture a variety of health outcomes, ranging from HRQoL to symptom severity. These include generic instruments that allow comparisons between different patient populations, as well as disease-specific measures targeted to those with specific conditions. ${ }^{8,10-12}$ It is widely held that children can report on their health validly and reliably using standardised PROM questionnaires from the age of 7 years ${ }^{13,14}$
${ }^{1}$ Life Course Epidemiology and Biostatistics Section, Population, Policy and Practice Programme, UCL Great Ormond Street Institute of Child Health, London, UK

${ }^{2}$ Great Ormond Street Hospital for Children NHS Foundation Trust, London, UK

${ }^{3}$ Ulverscroft Vision Research Group, London, UK

${ }^{4}$ National Institute for Health Research (NIHR) Biomedical Research Centre at Moorfields Eye Hospital NHS Foundation Trust and UCL Institute of Ophthalmology, London, UK

${ }^{5}$ Child Vision PROMs group members are listed above references.

\section{Correspondence:} JS Rahi, Life Course Epidemiology and Biostatistics Section, Population, Policy and Practice Programme, UCL Great Ormond Street Institute of Child Health, 30 Guilford Street, London WC1N 1EH, UK Tel: +44 (0)20 7905 2250; Fax: +44 (0)20 79052381 . E-mail: j.rahi@ucl.ac.uk

Received: 20 September 2016 Accepted in revised form: 25 November 2016 Published online: 13 January 2017 
(and possibly as early as 5 years ${ }^{10,15}$ ), given the opportunity and the child-friendly means to do so. Nevertheless, important practical and methodological challenges exist in developing and applying self-report questionnaires for children. ${ }^{10,13,14,16-18}$

Working with specialist clinical populations such as those with visual impairment (VI) potentially exacerbates these challenges. There has been limited investigation of these challenges and of approaches to addressing them. Thus, we undertook a review of the literature in this area, complemented by drawing on experimental data and experience from our own programme of research developing a suite of age-appropriate vision-specific PROMs of two types, one assessing vision-related quality of life (VQoL) ${ }^{19}$ and the other functional vision $(F V)^{20}$ of children and young people with VI. Although the need for such measures is widely accepted, the recent rush to develop vision-specific, child-centred $\mathrm{PROMs}^{21}$ has not been fully informed by understanding of the characteristics and needs of visually impaired children as questionnaire respondents. We present here a synthesis of the literature with lessons learned from our research, so as to spark debate about the direction of travel for PROMs for childhood visual disability.

\section{Need for vision-specific proms in paediatric ophthalmology}

Childhood onset VI has significant impact on the developing person, with cumulative consequences for their social-emotional functioning, cognitive development, education, and future prospects. ${ }^{22-26}$ Most visually impairing disorders affecting children in developed countries are not currently treatable or preventable, so a substantial focus of paediatric ophthalmology is on support, visual habilitation and maintenance of vision of affected children, rather than restorative treatments. ${ }^{27,28}$ A critical part of the ongoing support provided by paediatric ophthalmology services is understanding children's own assessment of the impact of their visual impairment on their daily lives, measured routinely and over time, to complement objective clinical assessments (such as acuity). Using PROMs to do this child-led assessment would allow for detection of changes in quality of life, participation or functional status in individual children and variation across a population of children both as a function of personal circumstances (eg, educational transitions, adverse life events), as well as clinical care and interventions.

Until recently, there was a paucity of valid and reliable vision-specific PROMs to capture children and young people's perspectives about their VI, and there were concerns that existing measures lacked in quality, as assessed by the 'gold standard' PROMs guidelines. ${ }^{29,30}$ In 2013 we completed a systematic review of available childappropriate PROMs for use in paediatric ophthalmology. ${ }^{21}$ In total, we identified 17 measures, 6 of which were suitable specifically for children and young people with visually impairing disorders as listed in Table 1 (for quality assessment refer to the existing review $\left.{ }^{21}\right)$. The rest are targeted to specific ophthalmic conditions. At the time of that review, based on a detailed quality assessment,

Table 1 Child-appropriate PROMs for children and young people with visual impairment (VI) (regardless of the VI cause)

\begin{tabular}{|c|c|c|c|c|}
\hline Construct measured & Instrument name & $\begin{array}{l}\text { Year and country of } \\
\text { development }\end{array}$ & $\begin{array}{l}\text { Languages the } \\
\text { instrument is } \\
\text { available in }\end{array}$ & Age range of respondents ${ }^{\mathrm{b}}$ \\
\hline \multirow[t]{4}{*}{$\begin{array}{l}\text { Functional vision/ } \\
\text { visual ability }\end{array}$} & $\begin{array}{l}\text { Cardiff Visual Ability Questionnaire } \\
(\text { CVAQC })^{39}\end{array}$ & 2010, UK & English & $\begin{array}{l}\text { Children and young } \\
\text { people aged 5-18 years }\end{array}$ \\
\hline & $\begin{array}{l}\text { LV Prasad-Functional Vision Questionnaire } \\
(\text { LVP-FVQ) }\end{array}$ & 2003, India & $\begin{array}{l}\text { Indian English, } \\
\text { Hindi, Telugu }\end{array}$ & $\begin{array}{l}\text { Children and young } \\
\text { people aged } 8-18 \text { years }\end{array}$ \\
\hline & $\begin{array}{l}\text { LV Prasad - Functional Vision Questionnaire } \\
\text { Second Version (LVP-FVQ II) }{ }^{41}\end{array}$ & 2012, India & $\begin{array}{l}\text { Indian English, } \\
\text { Hindi, Telugu }\end{array}$ & $\begin{array}{l}\text { Children and young } \\
\text { people aged 8-16 years }\end{array}$ \\
\hline & $\begin{array}{l}\text { Functional Vision Questionnaire for Children } \\
\text { and Young people (FVQ_CYP) }\end{array}$ & 2013, UK & English & $\begin{array}{l}\text { Children and young } \\
\text { people aged } 10-15 \text { years }\end{array}$ \\
\hline \multirow[t]{3}{*}{$\begin{array}{l}\text { Vision-related } \\
\text { quality of life }\end{array}$} & $\begin{array}{l}\text { Children's Visual Function Questionnaire } \\
(\mathrm{CVFQ})^{42,43}\end{array}$ & 2004, USA & English & $\begin{array}{l}\text { Children aged } 0-7 \text { years } \\
\text { (parent-reported) }\end{array}$ \\
\hline & $\begin{array}{l}\text { The impact of vision impairment on children } \\
\text { (IVI_C })^{44,45}\end{array}$ & 2011, Australia & English & $\begin{array}{l}\text { Children and young } \\
\text { people aged } 8-18 \text { years }\end{array}$ \\
\hline & $\begin{array}{l}\text { Vision-related Quality of Life of Children \& } \\
\text { Young People (VQoL_CYP) }\end{array}$ & 2011, UK & English & $\begin{array}{l}\text { Children and young } \\
\text { people aged } 10-15 \text { years }\end{array}$ \\
\hline
\end{tabular}

adapted from: Tadić et al ${ }^{21}$ see the paper also for a detailed outline of other eye disorder specific instruments for use in Paediatric Ophthalmology. ${ }^{\mathrm{b}}$ All instruments are suitable for self-reporting by children/young people, apart from the CVFQ, which is intended as a proxy/parent reported instrument. 'The FVQ_CYP was developed after the original review (from which this table was adapted) was published. 
we found that only a small number of instruments were in a sufficiently advanced stage psychometrically to be recommended for use in clinical care illustrating significant challenges of developing robust child-appropriate PROMs. These challenges, which likely explain the lack of appropriate measures, are discussed in more detail below.

\section{Challenges and opportunities}

As highlighted above, the paucity of high quality PROMs for visually impaired children is not surprising. PROM development is a time-consuming, labour-intensive, iterative, and reflective process. It involves a set of methodologically rigorous and complex stages, each dependent on capturing information from the target patient population to ensure its relevance, reliability and validity. Conventionally, this starts with interviewing the target patient groups to determine the content, as well as comprehensibility and practical aspects of the questionnaire, followed by piloting and formal evaluation with representative samples. Adherence to these methodological principles and robust methodology is harder to achieve in development and application of paediatric PROMs because of the additional considerations and challenges relating to children. ${ }^{18,31}$ In Table 2 we summarise the key recommendations and good practices extracted from the literature relating to developing and applying PROMs for children in general. Crucially, there are a number of specific additional considerations for children with visually impairing disorders, which we also present in Table 2 and further discuss below.

\section{Theoretical underpinning of PROM constructs}

PROMs are used to assess a variety of different constructs (eg, HRQoL, functional status). A firm grasp of the theoretical underpinning of the construct to be measured is critical in order to make accurate inferences about outcomes. ${ }^{8}$ However, in the ophthalmic literature there is frequent conflation of the related, but distinct constructs of VQoL, FV and visual functions (typically acuity), which together describe the impact of impaired vision on an individual. ${ }^{21,32}$ Importantly, in keeping with the established phenomenon of the 'disability paradox', which describes persons with severe illnesses or disabilities nevertheless experiencing and reporting good quality of life, ${ }^{33}$ poor eyesight does not necessarily mean extreme functional limitations or reduced emotional and social fulfilment, as assessed by the affected individual. This has important implications for how 'the impact of visual disability' should be viewed and measured by professionals. By conflating these constructs, for instance by using FV measures to assess VQoL in children with VI and vice versa, or by assuming poor QoL based on reduced visual functions in a child, clinicians risk inaccurate inferences about the effectiveness of treatment and interventions. A truly individualised and comprehensive assessment of the impact of VI, through complementary but not interchangeable PROMs, would capture self-reported FV and as VQoL as adjuncts to objective clinical assessments.

\section{Developmental or age-appropriate PROMs?}

Developmental issues must be considered so as to ensure PROMs appropriate for children of different ages as well as with different cognitive and communication abilities. ${ }^{18}$ Cognitive development determines children's ability to engage in questionnaire development activities (eg, interviews and focus groups), as well as in the questionanswer process involved in questionnaire completion. ${ }^{13,14}$ For instance, the understanding of and vocabulary required for the concepts being assessed, the issues that children perceive as important (and which should inform the instrument content) and the format of the instrument (including the number and type of response options or time-frame used) all vary by age. ${ }^{14}$ Engagement with a PROM relies on language, reading skills and memory, all of which are still developing in early school years. ${ }^{13}$ Reliability and validity of children's responses also improve with age. ${ }^{15,18}$ Thus, understanding of typical developmental stages should inform age thresholds for age-appropriate questionnaire versions; however this is not straight forward because of the individual variations within age groups. ${ }^{18}$ In terms of visually impaired children, superimposed on this is the challenge that VI from birth or infancy results in delay in key developmental milestones ${ }^{23}$ and applying age-specific criteria to development of PROMs becomes even more difficult. Thus, we suggest that for children with VI developmentally-appropriate as opposed to ageappropriate questionnaires may be more apposite. Further research is required to delineate thresholds, comprising a combination of qualitative and quantitative techniques to capture relevant content with reliability and adequate sample size at the upper and lower bounds of the target age range to test developmentally appropriate cut offs. ${ }^{18}$

\section{Flexible versus standard PROM formats}

We propose that the notion of a 'standard' questionnaire format needs to be revisited. Questionnaires are by nature visual tools (even when presented electronically or large print), posing substantial challenges for usability by children with a range of levels of VI. For instance, recommendations concerning response choices are based 
Table 2 A summary of recommendations for developing and applying patient-reported outcome measures (PROMs) for children, including specific recommendations for children with visual impairment

Considerations and recommendations for development and application of PROMs for children Specific recommendations relating to children with in general (modified from Matza et al ${ }^{18}$ and Morriss et al $\left.{ }^{8}\right)^{\mathrm{a}}$ visual impairment

The importance of the theoretical underpinning of PROMs

Child PROMs need to be developmentally appropriate

Age-appropriate formats and administration methods

Self-report vs. proxy report. If proxy is used - when, by whom and why?

A child-targeted PROM should be grounded in children's voices and be psychometrically robust
PROMs assess a variety of constructs (eg, quality
of life, wellbeing, health status, functional status)
so the purpose of measurement should be clearly
defined at the outset as not to conflate the
underlying constructs.
Child PROMs need to be developmentally
appropriate but because of variability in children's
development and abilities, there is no fixed agedevelopment and abilities, there is no fixed age-
related criterion for judging when children can reliably complete a PROM. ${ }^{8,18}$ Matza et al ${ }^{18}$ recommend 4 key age groups as a starting point for making decisions about age-appropriate PROM administration (1. below 5 years, 5 to 7 years: child-report is possible, but reliability and validity often questionable, 2. 8-11 years: reliability and validity of child-report improves, 3 . 12-18 years: self-report is preferred). However, it is recommended that specific age cut-offs should be determined individually for each PROM (developed and validated with adequate sample size at the upper and lower bounds of the target age range) and tested with cognitive interviews in each new target population. ${ }^{18}$

Child-centred PROMs should be designed and formatted appropriately for the target age group, ${ }^{8,18}$ including considerations of healthrelated vocabulary and reading level, response scale, recall period, instrument length, pictorial representations, formatting, methods or administration and electronic data collection. ${ }^{18}$ Content validity of a child PROM should be established with children. Children should be included in the early qualitative research stages (through interviews and focus groups) conducted to determine that the content of the PROM is relevant and comprehensible to children. ${ }^{18}$ A PROM also needs to be psychometrically robust, demonstrating reliability, validity, responsiveness, precision, interpretability, acceptability, and feasibility. ${ }^{8}$

Children's own self-report should be encouraged and collected whenever possible ${ }^{8,18}$ Proxy-reports (eg, by parents, teachers or clinicians) can be used if children are unable to self-report (due to age or cognitive limitations), but attention should be given to considering 'who' is the best proxy and 'why' in a given context. ${ }^{18}$ If proxy-reports are used these must not be aggregated with self-reports. ${ }^{8}$ Ideally, where both child and parent versions of a PROM are available, both should be collected to help interpret results when children's selfreports are unavailable. ${ }^{8}$

Content validity and measurement properties of a paediatric PROM may not transfer to a different cultural setting and will need to be re-examined within each new culture where it is being used. ${ }^{18}$
Vision-related outcomes of interests (eg, visionrelated quality of life vs. visual ability) need to be clearly distinguished and measured with appropriate PROMs.

With available PROMs, age-related boundaries may need to be treated flexibly because of varying degrees of a delay in acquisition of key developmental milestones associated with significant visual impairment from infancy (eg, consider if a form intended for 5-7 year old children may or may not be more appropriate for a visually impaired 8 year old).

If existing PROMs with set age-appropriate cut offs are used, it should be reported if these were used flexibly to account for developmental variation in visually impaired children and this should be considered in interpretation of scores/ findings.

Flexible formats and administration approaches need to be considered and/or developed for children with differing levels of visual impairment of different ages to enable selfreporting whenever possible.

The reality and implications of small sample sizes when developing and applying PROMs for visually impaired children, due to the rarity of the population, need to be recognised and considered in interpreting the findings. The sources of potential bias (eg, lower response rates by families from more socio-economically deprived subgroups) should be recognised and reported.

'Flexibility' should be allowed for different levels of self-reporting ability in children with different levels of visual impairment who may require different levels of adult input to complete a PROM (eg, reading and scribing for blind children). Appropriate instructions should be provided for the adults (parents or professionals) to allow them to help, where required, the child to 'self-report', without influencing the child's response.

Information on whether and what kind of help was needed should be recorded systematically and its impact on the child's responses should be assessed.

Cross-cultural issues 
on research with sighted children. ${ }^{14}$ Many questionnaires developed for sighted children also include pictures (eg, smiley faces), based on the assumption that pictures help children maintain interest and attention and clarify the response process, ${ }^{10,18}$ but this would be difficult to implement for children with varying degrees of VI. Even with normally sighted children it is assumed that information presented visually will be integrated and facilitate the question-answer process. But visually impaired children have to work hard to manipulate questionnaire information presented either visually (for those without useful residual vision) or verbally before they can engage with the issues targeted by any given questionnaire, requiring additional memory and attention workload irrespective of cognitive ability. Thus, their true ability to report on complex issues, such as those relating to QoL, could be buried by a standardised questionnaire design and its associated administrative burden.

Significant expertise is required to develop innovative and flexible child-centred approaches, with questionnaires individually adapted in size, format (eg, audio-assisted for more severe VI) or colour as required to facilitate self-reporting and ensure data quality. While this challenges the notion of 'standard' questionnaire methodology, we suggest this flexibility is the reality of developing and applying questionnaires that are suitable for the unique paediatric population of children with VI and align with the principles of 'personalised medicine'.

\section{Self-reporting}

The third issue we would highlight is the feasibility of selfreporting by children. The default position in the paediatric PROM literature is that even children between ages 5-7 years can reliably self-report without parents as proxies, but evidence about the nature and intricacies of self-reporting by children remains limited. Our experience in a study that involved a postal survey with around 100 children with VI aged 10-15 years is that almost half needed some parental help with questionnaire completion, including reading and scribing the answers as well as clarifying some questions; this was not confined only to younger participants or those with more severe impairment. ${ }^{19}$ We found that even some older visually impaired teenagers who are developmentally and cognitively well placed to self-report may rely on basic help with reading and scribing. However, the presence of an adult as 'scribe' or 'interpreter' in the process may be sufficient to influence responses (or lead to non-response ${ }^{13}$ ), especially where there is disclosure on sensitive topics relating to privacy and social life. Conversely, PROM completion in healthcare settings, where questionnaire administration is facilitated by a professional rather than parent, is not always feasible nor, where achieved, necessarily satisfactory as full privacy and sufficient time for reflection cannot be guaranteed. Researchers and clinicians working with visually impaired children, as well as other paediatric populations with complex needs, may need to move away from the narrow definition of self-reporting as applied to adults. To capture children's views it may be necessary to embrace the reality of varying levels of selfreport ability and respond flexibly to the need for help by a parent or professional, combined with capturing the information on whether and what help was needed and assessing its impact on the child's responses. Our approach, for example, included providing appropriate instructions for the parents and supplying a complementary parent-specific instrument version to capture parents' own perspectives of the same health outcome for their child, thereby positively harnessing their gate-keeping role and influence.

\section{Epidemiological, statistical, and ethical considerations}

Finally, the related issues of statistical challenges, ethical constraints and implications of unrepresentative samples for policy need to be considered. PROM development, especially psychometric validation, depends on large and representative sample sizes. However, researchers rarely report participation rates or address low or biased participation. Visually impaired children are a complex, heterogeneous and numerically small population who are also hard to reach. ${ }^{28,34}$ For example, our participation rates in studies of VQoL were on average $30 \%$, comparable (where reported) to those in other similar research, 34,35 but the potential impact in terms of both power and bias is disproportionately greater when the total population is smaller. We suggest that in studies of children with VI (and uncommon disorders in general) it may be necessary to rethink the balance between statistical significance levels and clinically significant findings. Related to this is the issue of biased participation relating to under-representation of certain groups such as ethnic minorities. ${ }^{34}$ Importantly, the cause of low participation rates may be children experiencing greater difficulties and thus being unwilling themselves (or their parents) to participate in studies that require disclosure of issues they find upsetting. This potentially impacts on how we capture and conceptualise 'low' HRQoL in children. Indeed, such bias in participation may also to an extent explain the trend for general skeweness towards better HRQoL in studies using generic measures. ${ }^{36,37} \mathrm{We}$ need to understand better what contributes to low and/or biased participation and to develop strategies to support families of affected children, especially from hard to reach groups, to take part. But there is a balance to be found and it is clearly unethical to persuade families to participate to ensure representative samples because there may be good reasons for declining. There is a need to explicitly recognise that bias exists in most studies and 
this can impact on equity if policy decisions are based on biased research.

\section{Conclusions}

There is a need for greater conceptual clarity and reflection, as well as increased pragmatism in development and application of PROMs intended for visually impaired children. Significant practical and methodological challenges in this field are widely recognised, but a 'one size fits all' methodological model currently prevails, driven by psychometric analytical trends. This does not align well with the complex paradigm of childhood VI and the values of 'personalised medicine'. Since the gold standards of PROM development ${ }^{30,38}$ were not developed with numerically small and heterogeneous populations of children with complex needs in mind, an imaginative reprofiling is required. Approaches would include formulating developmentally appropriate versus age-appropriate instruments with flexible formats and administration methods to facilitate self-reporting by children, as well as to ensure data quality. Equally, investment of time and resources would allow development of sensitive familycentred instructions and information sheets that capitalise on parents' positive role in the research process and facilitate their understanding of the need to capture their child's as well as their own unique perspectives. Finally, acceptance, awareness and explicit reporting of the existence of participation biases would help improve the relevance and scope of use of PROMs for policy.

Clinicians and academics need to engage in dialogue about these issues. As well as developing and applying robust age-appropriate vision-specific PROMs for children with VI, more research that focuses on visually impaired children as questionnaire respondents is also critical, but will require appropriate financial and infrastructure resources and multidisciplinary expertise. Understanding the unique nature and characteristics of their ability and needs as respondents will contribute to development of quality PROMS with meaning and traction in 'real life' clinical practice as well as research.

\section{Conflict of interest}

The authors declare no conflict of interest.

\section{Acknowledgements}

We would like to acknowledge all the colleagues from the following UK hospitals who helped with patient identification and recruitment: Birmingham Children's Hospital, Bradford Royal Infirmary (Bradford Teaching Hospitals NHS Foundation Trust), Bristol Eye Hospital
(University Hospitals Bristol), Addenbrooke's Hospital (Cambridge Univeristy Hospitals), Royal Derby Hospital, St James's University Hospital (Leeds Teaching Hospitals), Pinderfields General Hospital (Mid Yorkshire Hospitals NHS Trust), Royal Victoria Infirmary Newcastle Upon Tyne Hospitals), University Hospital of North Staffordshire, Royal Devon and Exeter Hospital (Wonford), Torbay Hospital (South Devon Healthcare NHS Foundation Trust), Southend Hospital Southend University Hospitals), University Hospital of Wales (Cardiff and Vale University Hospital Board, Cardiff) and West Suffolk Hospital (Bury St Edmunds). The work reported here was funded by the grants from Guide Dogs for the Blind Association (OR2006-03b) and Fight for Sight (2014 and 1321/1322) and was undertaken at UCL Institute of Child Health/ Great Ormond Street Hospital and Moorfields Eye Hospital/UCL Institute of Ophthalmology, both of which are members of UCL Partners Academic Health Science Centre (AHSC), and both receive a proportion of funding from the Department of Health's National Institute of Health Research (NIHR) Biomedical Research Centres funding scheme. Members of our research team are supported by the Ulverscroft Foundation. Further support was received from the following sources: National Institute of Health Research (NIHR) Biomedical Research Centre at Moorfields Eye Hospital NHS Foundation Trust and UCL Institute of Ophthalmology, and NIHR Central and East London Comprehensive Research Network. The Life Course Epidemiology and Biostatistics Section within the Population, Policy and Practice Programme at UCL Institute of Child Health was previously supported in part by the Medical Research Council in its capacity as the MRC Centre of Epidemiology for Child Health (award G0400546).

\section{Members of the Child Vision PROM group}

Contribution of members of the Child Vision PROM group (Phillippa Cumberland, Naomi Dale, Peng Tee Khaw, Gillian Lewando Hundt, Alki Liasis, Anthony Moore, Alison Salt, David Taylor) and the study research and advisory group (Corie Brown, Marianne Craig, Christine Ennals, Sarah Keeley, Jackie Osborne, Alexandra Robertson, Nidhi Sobti, Paula Thomas, Lucy Thompson and Jude Thompson).

\section{References}

1 Darzi A. High Quality Care for All: NHS Next Stage Review Final Report. Department of Health: London, 2008. 
2 Groene O. Patient centredness and quality improvement efforts in hospitals: rationale, measurement, implementation. Int J Qual Health Care 2011; 23(5): 531-537.

3 Health Do. Equity and Excellence: Liberating the NHS. HMSO: London, 2010.

4 (PCORI) P-CORI. National Priorities and Research Agenda. 2013. http://www.pcori.org/ (accessed 24 April 2013).

5 Black N. Patient reported outcome measures could help transform healthcare. BMJ 2013; 346: f167.

6 Fitzpatrick R, Davey C, Buxton M, Jones D. Evaluating patient-based outcome measures for use in clinical trials: a review. Health Technol Assess 1998; 2(14): 1-74.

7 Black N, Varaganum M, Hutchings A. Relationship between patient reported experience (PREMs) and patient reported outcomes (PROMs) in elective surgery. BMJ Qual Saf 2014; 23: 534-542.

8 Morris C, Gibbons E, Fitzpatrick R. Child and parent reported outcome measures: a scoping report focusing on feasibility for routine use in the NHS. A report to the Department of Health, 2009: Patient-Reported Oucome Measures Group. Department of Public Health. University of Oxford, 2009.

9 Department of Health \& Department for Children SaF. Healthy Lives, Brighter Futures - The Strategy for Children and Young People's Health. London, UK. 2009.

10 Eiser C, Morse R. Quality-of-life measures in chronic diseases of childhood. Health Technol Assess 2001; 5(4): 1-157.

11 Bullinger M, Ravens-Sieberer U. Health related quality of life assessment in children: a review of the literature. Eur Rev Appl Psychol 1995; 45(4): 245-256.

12 Janssens A, Thompson Coon J, Rogers M, Allen K, Green C, Jenkinson $\mathrm{C}$ et al. A systematic review of generic multidimensional patient-reported outcome measures for children, Part I: descriptive characteristics. Value Health 2015; 18(2): 315-333.

13 Scott J. Children as respondents: methods for improving data quality. In: Lyberg L, Biemer P, Collins M, De Leeuw E, Dippo C, Schwarz N, Trewin D (eds). Survey Measurement and Process Quality. John Wiley \& Sons, Inc.: New York, NY, USA, 1997; pp 331-350.

14 Borgers N, de Leeuw E, Hox J. Children as respondents in survey research: cognitive development and response quality 1. Bull Méthodol Sociol 2000; 66(1): 60-75.

15 Varni J, Limbers C, Burwinkle T. How young can children reliably and validly self-report their health-related quality of life?: An analysis of 8591 children across age subgroups with the PedsQLTM 4.0 Generic Core Scales. Health Qual Life Outcomes 2007; 5(1): 1.

16 Borgers N, Hox J, Sikkel D. Response quality in survey research with children and adolescents: the effect of labeled response options and vague quantifiers. Int J Public Opin Res 2003; 15(1): 83-94.

17 Borgers N, Sikkel D, Hox J. Response effects in surveys on children and adolescents: the effect of number of response options, negative wording, and neutral mid-point. Quality Quantity 2004; 38(1): 17-33.

18 Matza LS, Patrick DL, Riley AW, Alexander J, Rajmil L, Pleil AM et al. Pediatric patient-reported outcome instruments for research to support medical product labeling: report of the ISPOR PRO good research practices for the assessment of children and adolescents task force. Value Health 2013; 16(4): 461-479.

19 Tadić V, Cooper A, Cumberland P, Lewando-Hundt G, Rahi J. Measuring the quality of life of visually impaired children: first stage psychometric evaluation of the novel VQoL_CYP instrument. PLoS One 2016; 11(2): e0146225.

20 Tadić V, Cooper A, Cumberland P, Lewando-Hundt G, Rahi JS. Development of the functional vision questionnaire for children and young people with visual impairment: the FVQ_CYP. Ophthalmology 2013; 120(12): 2725-2732.

21 Tadić V, Hogan A, Sobti N, Knowles RL, Rahi JS. Patient reported outcome measures (PROMs) in paediatric ophthalmology: a systematic review. Br J Ophthalmol 2013; 97(11): 1369-1381.

22 Keil S. Survey of educational provision for blind and partially sighted children in England Scotland and Wales in 2002. Br J Vis Impair 2003; 21: 93-97.

23 Dale N, Edwards L, Thapar A et al. Children with specific sensory impairments. In: Thapar A, Leckman JF, Scott S, Snowling MJ, Taylor EA (eds). Rutter's Child and Adolescent Psychiatry, 6th edn. John Wiley \& Sons, Ltd: Chichester, West Sussex, UK, 2015. pp612-622.

24 Kef S. Psychosocial adjustment and the meaning of social support for visually impaired adolescents. J Visual Impairment Blindness 2002; 96(1): 22-37.

25 Warren DH. Blindness and Children: An Individual Differences Approach. Cambridge University Press: Cambridge, UK, 1994.

26 Shaw A, Gold D, Wolffe K. Employment-related experiences of youths who are visually impaired: how are these youths faring? J Vis Impairment Blind 2007; 101(1): 7-21.

27 Solebo AL, Rahi J. Epidemiology, aetiology and management of visual impairment in children. Arch Dis Child 2014; 99(4): 375-379.

28 Rahi JS, Cable N. Severe visual impairment and blindness in children in the UK. Lancet 2003; 362(9393): 1359-1365.

29 Mokkink L, Terwee C, Knol D, Stratford PW, Alonso J, Patrick DL et al. Protocol of the COSMIN study: COnsensusbased Standards for the selection of health Measurement INstruments. BMC Med Res Methodol 2006; 6(1): 1-7.

30 Reeve B, Wyrwich K, Wu A, Velikova G, Terwee CB, Snyder CF et al. ISOQOL recommends minimum standards for patient-reported outcome measures used in patientcentered outcomes and comparative effectiveness research. Qual Life Res 2013; 22(8): 1889-1905.

31 Arbuckle R, Abetz-Webb L. 'Not just little adults': qualitative methods to support the development of pediatric patientreported outcomes. Patient-Patient-Centered Outcomes Res 2013; 6(3): 143-159.

32 Colenbrander A. Assessment of functional vision and its rehabilitation. Acta Ophthalmol (Copenh) 2010; 88(2): 163-173.

33 Albrecht GL, Devlieger PJ. The disability paradox: high quality of life against all odds. Soc Sci Med 1999; 48(8): 977-988.

34 Tadić V, Hamblion EL, Keeley S, Cumberland P, Hundt GL, Rahi JS. 'Silent Voices' in health services research: ethnicity and socioeconomic variation in participation in studies of quality of life in childhood visual disability. Invest Ophthalmol Vis Sci 2010; 51(4): 1886-1890.

35 Hamblion EL, Moore AT, Rahi JS. The health-related quality of life of children with hereditary retinal disorders and the psychosocial impact on their families. Invest Ophthalmol Vis Sci 2011; 52(11): 7981-7986.

36 Felder-Puig R, Frey E, Proksch K, Varni JW, Gadner H, Topf R. Validation of the German version of the Pediatric Quality of Life InventoryTM (PedsQLTM) in childhood cancer patients off treatment and children with epilepsy. Qual Life Res 2004; 13(1): 223-234. 
37 Varni JW, Seid M, Rode CA. The PedsQL ${ }^{\mathrm{TM}}$ : measurement model for the pediatric quality of life inventory. Med Care 1999; 37(2): 126-139.

38 Mokkink LB, Terwee CB, Patrick DL, Alonso J, Stratford PW, Knol DL et al. The COSMIN checklist for assessing the methodological quality of studies on measurement properties of health status measurement instruments: an international Delphi study. Qual Life Res 2010; 19(4): 539-549.

39 Khadka J, Ryan B, Margrain TH, Court H, Woodhouse JM. Development of the 25-item Cardiff Visual Ability Questionnaire for Children (CVAQC). Br J Ophthalmol 2010; 94(6): 730-735.

40 Gothwal VK, Lovie-Kitchin JE, Nutheti R. The development of the LV Prasad-Functional Vision Questionnaire: a measure of functional vision performance of visually impaired children. Invest Ophthalmol Vis Sci 2003; 44(9): 4131-4139.

41 Gothwal VK, Sumalini R, Bharani S, Reddy SP, Bagga DK. The second version of the L. V. Prasad-functional vision questionnaire. Optom Vis Sci 2012; 89(11): 1601-1610.

42 Birch EE, Cheng CS, Felius J. Validity and reliability of the Children's Visual Function Questionnaire (CVFQ). J Aapos:
Am Assoc Pediatric Ophthalmol Strabismus 2007; 11(5): 473-479.

43 Felius J, Stager DR Sr., Berry PM, Fawcett SL, Stager DR Jr, Salomão SR et al. Development of an instrument to assess vision-related quality of life in young children. Am J Ophthalmol 2004; 138(3): 362-372.

44 Cochrane GM, Marella M, Keeffe JE, Lamoureux EL. The Impact of Vision Impairment for Children (IVI_C): validation of a vision-specific pediatric quality-of-life questionnaire using Rasch analysis. Invest Ophthalmol Vis Sci 2011; 52(3): 1632-1640.

45 Cochrane G, Lamoureux E, Keeffe J. Defining the content for a new quality of life questionnaire for students with low vision (the Impact of Vision Impairment on Children: IVI_C). Ophthalmic Epidemiol 2008; 15(2): 114-120.

46 Rahi JS, Tadić V, Keeley S, Lewando-Hundt G. Visionrelated Quality of Life G. Capturing children and young people's perspectives to identify the content for a novel vision-related quality of life instrument. Ophthalmology 2011; 118(5): 819-824. 